Journal of Environmental and Agricultural Studies

ISSN: $2710-140$

DOI: $10.32996 /$ jeas

Journal Homepage: www.al-kindipublisher.com/index.php/jeas

JAES

\title{
Use of Body Linear Measurements to Estimate Live Weight in Communal Beef Cattle
}

\author{
Wesly Soul $\mathbf{3} \square$ and Bvirwa Wesley and Nyamushamba Godfrey $B^{3} \mathbf{8}$ \\ ${ }^{1}$ Department of Livestock, Wildlife \& Fisheries, Great Zimbabwe University P.O Box 1235 Masvingo, Zimbabwe \\ ${ }^{23}$ Department of Agriculture, Women's University in Africa, 549 Arcturus Road, Harare, Zimbabwe
}

$\triangle$ Corresponding Author: Washaya Soul, E-mail: jabulaniwashya@yahoo.com

\author{
ARTICLE INFORMATION \\ Received: August 08, 2021 \\ Accepted: September, 14, 2021 \\ Volume: 2 \\ Issue: 2 \\ DOI: 10.32996/jeas.2021.2.2.2
}

\section{KEYWORDS}

Body weight, collinearity, beef cattle, indigenous breeds.

\section{ABSTRACT}

Body measurements are important criteria in the selection of elite animals for breeding. The objective of this study was to determine the relationship, accuracy of prediction of body weight from body measurements, and identifying multicollinearity from three beef breeds. Four classes of stock (bull, cows, steers, and heifers) were considered. Correlation, simple, and multiple linear regression models were fitted with body weight (BW) as the dependent variable and body length (BL), heart girth (HG), height at wither (HW), muzzle circumference (MC), and shank circumference (SC) as the independent variables. The BW of the animals ranged from 218 to $630 \mathrm{~kg}$, the least being heifers and bulls were the heaviest. The pairwise phenotypic correlations showed a high and significant positive relationship between BW and body dimensions ( $r=0.751-0.96 ; P<0.01)$. However, negative correlations were observed between BW with $B L$ and $M C$ of $r=-0.733$ and 0.703 and $-0.660,-0.650$, for cows and heifers, respectively. Regressing BW on BL, HG, and $\mathrm{HW}$ measurements gave statistically significant $(P<0.01)$ equations with $\mathrm{R} 2$ ranging from 0.60 to 0.79 . Collinearity, as portrayed by high variance inflation factors (VIFs), tolerance values, and low eigenvalues, was evident in four of the variables. It was concluded that the regression model was useful in BW prediction for smallholder farms and the relationship between $\mathrm{BW}$ and other body measurements was influenced by breed and class of stock. It is recommended that ridge regression or principal component regression be used in cases where multicollinearity exisists.

\section{Introduction}

The use of linear body measurements has been proven useful in predicting cattle's live weight (Lukuyu et al., 2016). In most subSaharan African countries where subsistence livestock production is the only system possible, record-keeping is completely absent, hence monitoring and corrective management activities involving assessment of growth rates, responses of animals to different diets, temperature changes and determination of feed requirements is difficult. The assertion by Putra et al.(2014) further confirmed that live weight (LW) is critical in determining feeding levels and breeding of ideal heifer's, thus corroborate with the ideal bull's weight prior to mating. Tebug et al. (2018) showed that LW is important in deciding the slaughter weight and treatment dose in livestock production. Furthermore, knowledge of animal weight and weight changes can be informative in determining the response of cattle to genetic selection. The globally acceptable methods of determining LW using either automated calibrated electronic/ mechanical scales or a simple weigh band are not practical in a smallholder farming context. In addition, where this equipment is available, technical competence to use and maintain them within these farming communities is limited (Kashoma et al., 2011; Musa et al., 2011 Tebug et al., 2018). It is sad and demeaning to learn that livestock traders use live weight estimates in determining the price of cattle at farm gate prices. This practice, to a large extent, underestimates by approximately $46 \%$ (Machila et al., 2008) that actual live weight (LW) devaluing local cattle translating into low prices that cannot support the financial needs for these communities. Numerous studies demonstrating the use of body linear measurements to estimate LW have focused to a greater extent on exotic beef, dairy and very few have exhaustively focused on indigenous cattle. In the same vein, Putra et al. (2014); Lukuyu et al. (2016) Tebug et al. (2018) and Ashwini et al. (2019) have indicated that body measurements play a significant

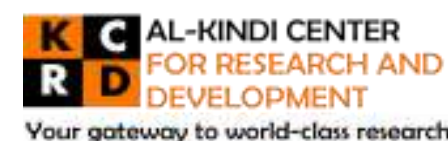

Your gateway to world-class research

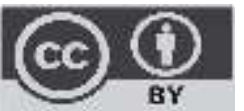

Published by Al-Kindi Center for Research and Development, London, United Kingdom. Copyright (c) the author(s). This open access article is distributed under a Creative Commons Attribution (CC-BY) 4.0 license 
role in evaluating breed performance thus distinguish animals through predictive equations. The prediction of live body weight is practical, faster, easier, and cheaper in the rural areas, using body measurements where the resources are insufficient for the breeder. In the absence of weighing scales, a common phenomenon in rural areas, this method should be used. In addition, the method can be used in the selection of elite cows for breeding where pedigree records are often unavailable. The relationship between body measurements and body weight depends upon a number of factors, including breed, age, type, condition of the animals (Ashwini et al., 2019). To the best of our knowledge, there isn't any record of such studies in Zimbabwe. Therefore the objective of this study was to estimate the body weights of three indigenous breeds in Gokwe North.

\section{Methodology}

\subsection{Study site description}

The study was conducted in communal areas of Gokwe North District, Midlands Province. Zimbabwe wards 8, 13, 14, 15 , and 36. The area is predominantly ecological region natural IV (61\%) which is characterized by moderate to low erratic rainfall (400 - 650 $\mathrm{mm}$ per annum) and a mean annual temperature of $20^{\circ} \mathrm{C}$. The area is prone to seasonal drought and dry spells during the rainy season. Major agricultural enterprises are dryland crop production and semi-intensive livestock production. The principal annual grasses include Eragrostis curvula, Digitaria species, Brachiaria species, and Chloris species. Perennial species include Heteropogon species, Cynodon dactylon, and Hyparrhenia species. The major vegetation type is the bush and woodland savanna dominated by Combretum species, Colophospermum mopane, Brachystegia species, acacia species, Terminalia serrica, and Dichrostachys species. The study area is shown in Figure 1.

\subsection{Data collection}

Identified cows (3-5 years of age), bulls ( 3 - 5 years of age), heifers (at least 1-year-old and not calved), and steers (2-4 years old) were weighed at a communal dip tank, servicing 5 wards, during their normal dipping procedure at fortnight intervals and three measurements were taken from the same animals. The dip tanks were within a $5 \mathrm{~km}$ radius; hence animals were all considered to be in the fasting state, thus variations due to gut-fill were negligible. Body measurements were taken by the same observer using an ordinary measuring tape as guided by FAO,(2012). Body length (BL) body weight (BW) muzzle circumference (MC), heart girth (HG) height at withers (HW), and shank circumference (SC) were the measured traits. The total number of cattle used was 1085 animals of which 73 were bulls, 326 cows, 343 steers, and 343 heifers. Approximately 362 animals from each breed were used at proportions of $6,8 \%$ bulls, $30 \%$ cows, $31,6 \%$ steers, and $31,6 \%$ heifers.

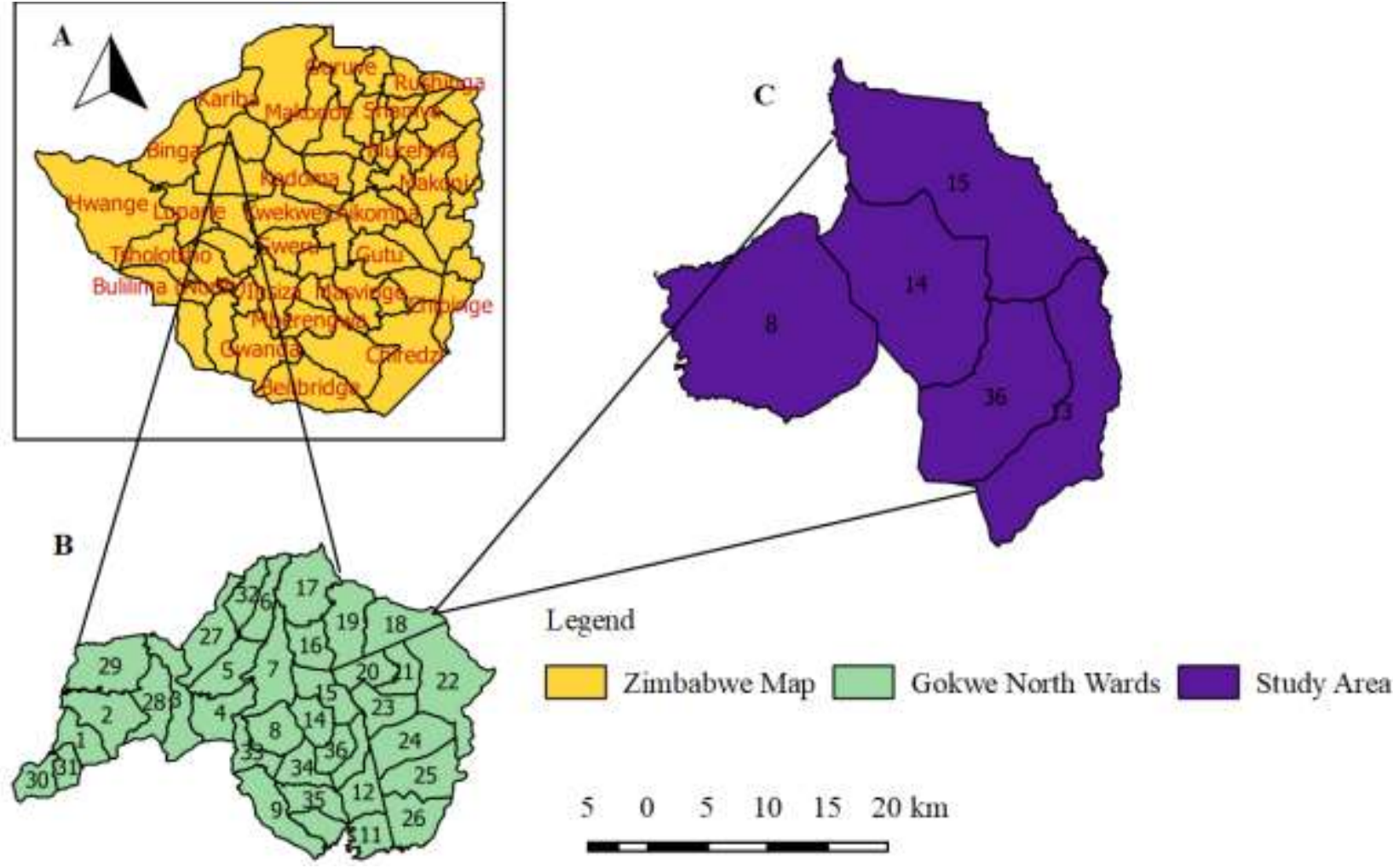

Figure 1 Showing A) The Zimbabwean Map, B) Gokwe North Wards, C) The Study area. 


\subsection{Statistical analysis}

Descriptive statistics were used to present the means of phenotypic measurements among the different breed groups and classes of stock. The associations between body weight and body measurements were estimated by Pearson's correlation coefficient. Simple and multiple linear regression was performed with phenotypic body measurements as continuous variables and breed and class of stock as categorical variables.

The model used was:

$$
\begin{aligned}
& Y=\beta_{0}+X_{1} X_{2} X_{3} X_{4} X_{5}+\text { error } \\
& \text { where } Y=B W, \beta_{0}=\text { the intercept, } X_{1}=B L, X_{2}=H G, X_{3}=H W X_{4}=M C, X_{5}=S C \text { and } e=\text { residual. }
\end{aligned}
$$

Two stepwise regression procedures using backward elimination were performed with variables $B L, H G$, and $H W, M C$ and SC (linear effects), and BW predictor. At first, the variables $(B L, H G$, and $H W)$ which were significant $(P<0.001)$ were retained in the model. The second stepwise regression procedure eliminated $\mathrm{BL}$ from the model. All measurements were used to evaluate multicollinearity. The prediction equations were tested for all animals and then separately for breeds and class of stock. We used the adjusted coefficient of (multiple) determination (adjusted $\mathrm{R}^{2}$ ) as an indicator of the amount of variance in BW explained by the model.

\section{Results and Discussion}

\subsubsection{Breed and class differences in body linear measurements}

The mean phenotypic parameters of the three breeds were evaluated and the results are shown in Table1. The BW of cattle observed ranged from 218 to $310 \mathrm{~kg}$ for heifers, 325 to 469 for cows, 370 to 496 for steers, and 413 to $630 \mathrm{~kg}$ for bulls. Afrikaner cattle had the lightest heifers while Tuli bulls were the heaviest. The average BL was 125.2, 122.4, and 108.73 for Tuli Afrikaner and Mashona, respectively. The highest average BL was 145.67 followed by $124.67,123$, and 82.67 for bulls, steers, cows, and heifers respectively. The average HW was $144.25,114.25$, and $117.75 \mathrm{~cm}$ for Tuli, Afrikaner, and Mashona respectively. Bulls showed the highest HW of 152.33 followed by $140.33,120.66$, and $89 \mathrm{~cm}$ for steers, cows, and heifers respectively. The average HG measurements ranged between 92.3 and $161 \mathrm{~cm}$. Bulls showed the highest HG followed by steers, cows, and heifers.

Table 1. Mean body weight (BW), heart girth $(\mathrm{HG})$, height at withers $(\mathrm{HW})$, body length $(\mathrm{BL})$ muzzle circumference $(\mathrm{MC})$, and

\begin{tabular}{|c|c|c|c|c|}
\hline Trait & Class of stock & Afrikaner & Mashona & Tuli \\
\hline \multirow[t]{4}{*}{$\mathrm{BL}$} & Mature Cows & $139.0 \pm 3.23$ & $114.3 \pm 3.26$ & $116.6 \pm 2.67$ \\
\hline & Bulls & $145.0 \pm 3.23$ & $135.0 \pm 3.23$ & $157.0 \pm 3.23$ \\
\hline & Steers & $116.0 \pm 3.23$ & $109.3 \pm 3.24$ & $149.8 \pm 3.23$ \\
\hline & Heifers & $93.1 \pm 20.49$ & $76.6 \pm 2.18$ & $78.2 \pm 1.79$ \\
\hline \multirow[t]{4}{*}{ BW } & Mature Cows & $325.7 \pm 17.37$ & $369.0 \pm 17.34$ & $463.2 \pm 10.68$ \\
\hline & Bulls & $526.7 \pm 17.36$ & $413.0 \pm 17.34$ & $630.0 \pm 17.34$ \\
\hline & Steers & $370.0 \pm 17.34$ & $368.0 \pm 17.34$ & $496.2 \pm 17.34$ \\
\hline & Heifers & $218.2 \pm 11.64$ & $247.2 \pm 11.62$ & $310.9 \pm 7.11$ \\
\hline \multirow[t]{4}{*}{$M C$} & Mature Cows & $54.2 \pm 0.76$ & $49.7 \pm 0.82$ & $45.6 \pm 1.22$ \\
\hline & Bulls & $55.0 \pm 0.75$ & $46.3 \pm 0.72$ & $54.3 \pm 0.71$ \\
\hline & Steers & $49.0 \pm 0.69$ & $49.8 \pm 0.69$ & $52.4 \pm 0.70$ \\
\hline & Heifers & $36.3 \pm 0.51$ & $33.3 \pm 0.55$ & $30.6 \pm 0.52$ \\
\hline \multirow[t]{3}{*}{ HW } & Mature Cows & $115.0 \pm 1.22$ & $126.7 \pm 1.27$ & $120.7 \pm 1.95$ \\
\hline & Bulls & $142.7 \pm 1.27$ & $136.0 \pm 1.22$ & $179.0 \pm 1.95$ \\
\hline & Steers & $123.8 \pm 1.22$ & $124.0 \pm 1.58$ & $173.27 \pm 1.96$ \\
\hline
\end{tabular}
shank circumference (SC) of smallholder beef cattle in Gokwe North. 


\begin{tabular}{|c|c|c|c|c|}
\hline & Heifers & $77.1 \pm 0.82$ & $84.9 \pm 0.85$ & $104.5 \pm 1.31$ \\
\hline \multirow[t]{4}{*}{ HG } & Mature Cows & $153.0 \pm 1.95$ & $140.7 \pm 1.96$ & $156.0 \pm 0.77$ \\
\hline & Bulls & $175.3 \pm 1.96$ & $162.0 \pm 1.95$ & $145.0 \pm 1.22$ \\
\hline & Steers & $154.0 \pm 1.95$ & $142.3 \pm 2.06$ & $142.8 \pm 1.30$ \\
\hline & Heifers & $102.5 \pm 1.31$ & $94.3 \pm 1.31$ & $80.4 \pm 0.82$ \\
\hline \multirow[t]{4}{*}{ SC } & Mature Cows & $39.4 \pm 0.62$ & $30.3 \pm 0.65$ & $32.6 \pm 0.62$ \\
\hline & Bulls & $36.7 \pm 0.71$ & $32.0 \pm 0.62$ & $38.0 \pm 0.62$ \\
\hline & Steers & $31.0 \pm 0.62$ & $29.3 \pm 0.71$ & $36.5 \pm 0.64$ \\
\hline & Heifers & $26.4 \pm 0.42$ & $20.3 \pm 0.43$ & $21.8 \pm 0.42$ \\
\hline
\end{tabular}

With respect to breeds, Afrikaner (146) animals showed higher HG measurements followed by Mashona (134.5) and lastly Tuli $(131.75 \mathrm{~cm})$. The least SC was observed in Mashona heifers $(20.3 \mathrm{~cm})$ while the highest was recorded for Afrikaner cows $(39.4 \mathrm{~cm})$. Afrikaner $(48.5 \mathrm{~cm})$ animals had bigger muzzles compared to Mashona $(44.75 \mathrm{~cm})$ and Tuli $(45.75 \mathrm{~cm})$ cattle.

\subsubsection{Correlation between body linear measurements}

The correlations among body linear measurements were evaluated and the result is shown in Table 2.

Table 2. The overall Pearsons' correlations of mean body weight (BW), heart girth (HG), height at withers (HW), body length (BL) muzzle circumference (MC), and shank circumference (SC) of smallholder beef cattle in Gokwe North.

\begin{tabular}{llllll}
\hline Correlations & & & & & \\
\hline MC & $\mathrm{MC}$ & $\mathrm{BL}$ & $\mathrm{BW}$ & $\mathrm{HG}$ & $\mathrm{HW}$ \\
$\mathrm{BL}$ & & & & & \\
$\mathrm{BW}$ & $.896^{* *}$ & & & & \\
$\mathrm{HG}$ & $.751^{* *}$ & $.777^{* *}$ & & & \\
$\mathrm{HW}$ & $.906^{* *}$ & $.888^{* *}$ & $.891^{* *}$ & & \\
$\mathrm{SC}$ & $.894^{* *}$ & $.871^{* *}$ & $.880^{* *}$ & $.960^{* *}$ & \\
\hline
\end{tabular}

**. Correlation is significant at the 0.01 level (2-tailed).

Table 3. Correlations by breed among mean body weight (BW), heart girth (HG), height at withers (HW), body length (BL) muzzle circumference (MC), and shank circumference (SC) of smallholder beef cattle in Gokwe North.

\begin{tabular}{|c|c|c|c|c|c|c|}
\hline Breed & & BW & $\mathrm{BL}$ & $M C$ & $\mathrm{HW}$ & $\mathrm{HG}$ \\
\hline \multirow[t]{6}{*}{ Afrikaner } & BW & & & & & \\
\hline & $B \mathrm{~L}$ & .819 & & & & \\
\hline & $\mathrm{MC}$ & .797 & .944 & & & \\
\hline & HW & .922 & .833 & .899 & & \\
\hline & $H G$ & .904 & .896 & .950 & .989 & \\
\hline & SC & .623 & .948 & .690 & .690 & .783 \\
\hline Mashona & BW & & & & & \\
\hline
\end{tabular}




\begin{tabular}{|c|c|c|c|c|c|c|}
\hline & $\mathrm{BL}$ & .105 & & & & \\
\hline & $M C$ & $.953^{* *}$ & .090 & & & \\
\hline & HW & $.936^{* *}$ & .143 & $.874^{* *}$ & & \\
\hline & $\mathrm{HG}$ & $.966^{* *}$ & .090 & $.900^{* *}$ & $.983^{* *}$ & \\
\hline & SC & $.958^{* *}$ & .183 & $.943^{* *}$ & $.964^{* *}$ & $.969^{* *}$ \\
\hline Tuli & BW & & & & & \\
\hline & $\mathrm{BL}$ & $.932^{* *}$ & & & & \\
\hline & $M C$ & $.891^{* *}$ & $.947^{\star *}$ & & & \\
\hline & $\mathrm{HW}$ & $.887^{* *}$ & $.947^{\star \star}$ & $.989^{* *}$ & & \\
\hline & HG & $.880^{* *}$ & $.964^{\star *}$ & $.989^{* *}$ & $.993^{* *}$ & \\
\hline & SC & $.892^{* *}$ & $.940^{* *}$ & $.989^{* *}$ & $.995^{\star *}$ & $.986^{* *}$ \\
\hline
\end{tabular}

**. Correlation is significant at the 0.01 level (2-tailed).

All body measurements showed a positive correlation to BW with BL exhibiting the highest correlation and SC having the least. Within body measurements, the highest correlation of $96 \%$ was between HG and HW. The correlation between breeds (Table 3) and among different classes of stock (Table 4) was also evaluated.

Table 4. Correlations by class of stock among mean body weight (BW), heart girth (HG), height at withers (HW), body length (BL) muzzle circumference (MC), and shank circumference (SC) of smallholder beef cattle in Gokwe North.

\begin{tabular}{|c|c|c|c|c|c|c|}
\hline & & $\mathrm{MC}$ & $\mathrm{BL}$ & BW & $\mathrm{HG}$ & $\mathrm{HW}$ \\
\hline \multirow[t]{6}{*}{ Bulls } & $M C$ & & & & & \\
\hline & $\mathrm{BL}$ & $.731^{\star \star}$ & & & & \\
\hline & BW & $.842^{\star *}$ & $.953^{* \star}$ & & & \\
\hline & $\mathrm{HG}$ & $.891^{* *}$ & $.916^{\star *}$ & $.929^{* *}$ & & \\
\hline & HW & $.875^{\star \star}$ & $.935^{* \star}$ & $.934^{* \star}$ & $.993^{* \star}$ & \\
\hline & SC & $.880^{* *}$ & $.918^{* *}$ & $.933^{* *}$ & $.973^{* *}$ & $.959^{* *}$ \\
\hline \multirow[t]{6}{*}{ Cows } & $\mathrm{MC}$ & & & & & \\
\hline & $\mathrm{BL}$ & $.924^{* *}$ & & & & \\
\hline & BW & $-.660^{* *}$ & $-.733^{* *}$ & & & \\
\hline & $H G$ & -.060 & -.036 & $.381^{*}$ & & \\
\hline & HW & -.357 & -.330 & $.392^{*}$ & $-.554^{* *}$ & \\
\hline & SC & $.702^{* \star}$ & $.758^{\star *}$ & $-.425^{*}$ & $.556^{* *}$ & $-.763^{* \star}$ \\
\hline \multirow[t]{5}{*}{ Steers } & $\mathrm{MC}$ & & & & & \\
\hline & $\mathrm{BL}$ & $.834^{\star \star}$ & & & & \\
\hline & BW & $.944^{\star *}$ & $.967^{* \star}$ & & & \\
\hline & $\mathrm{HG}$ & $.728^{* *}$ & $.965^{\star \star}$ & $.901^{\star \star}$ & & \\
\hline & HW & $.809^{\star \star}$ & $.967^{* \star}$ & $.941^{* \star}$ & $.891^{* \star}$ & \\
\hline
\end{tabular}




\begin{tabular}{|c|c|c|c|c|c|c|}
\hline & SC & $.801^{\star \star}$ & $.980^{* \star}$ & $.946^{* *}$ & $.945^{* *}$ & $.967^{* \star}$ \\
\hline \multirow[t]{6}{*}{ Heifers } & $M C$ & & & & & \\
\hline & $\mathrm{BL}$ & $.944^{* \star}$ & & & & \\
\hline & BW & $-.650^{* *}$ & $-.703^{* *}$ & & & \\
\hline & $\mathrm{HG}$ & -.040 & -.032 & $.481^{*}$ & & \\
\hline & HW & -.337 & -.320 & $.492^{*}$ & $-.454^{* \star}$ & \\
\hline & SC & $.752^{\star \star}$ & $.858^{\star \star}$ & $-.325^{*}$ & $.656^{* \star}$ & $-.663^{* *}$ \\
\hline
\end{tabular}

BW had a strong correlation with MC, HW, HG, and SC for Tuli and Mashona cattle, however, BW had a low correlation with BL for Mashona ( $r=0.11)$ and a moderate correlation SC for Afrikaner $(r=0.62)$. Low correlations were also observed between $B L$ and $\mathrm{MC}(r=0.09), \mathrm{HW}(r=0.14)$ and SC $(r=0.18)$ in Mashona cattle. Almost perfect positive correlations were observed between $\mathrm{HG}$ with HW ( $r=0.993)$ and HW with SC ( $r=0.995)$ in Tuli cattle. High correlations among traits were observed in Tuli cattle followed by Afrikaner and lastly Mashona. Across all breeds, HG and HW were the most related traits to weight and their correlations fall between $0.880-0.996$. Negative correlations were observed in cows and heifers only. There was a negative correlation between $B W$ with $B L$ and $M C$ of $r=-0.733$ and -0.703 and $-0.660,-0.650$, for cows and heifers respectively. Across all classes of stock BW also had a weak negative correlation with $\mathrm{HW}$. BW had a strong correlation with $\mathrm{BL}, \mathrm{HG}$, and $\mathrm{HW} r=>0.90$ in both steers and bulls while the relationship is weak to moderate in cows and heifers respectively. The highest correlation was observed in bulls between $\mathrm{HG}$ and HW of $r=0.993$ and the weakest relationship was between BW and $B L$ in cows $(r=-0.773)$.

\subsubsection{Regression of body weight on body linear measurements}

Prediction equations of BW from BL, HG, and HW for overall, breeds and class of stock are presented in Table 5. The simple regression predictions showed that $H G$ is the only single factor that can accurately estimate $B W$ in cattle with an $R^{2}$ value of $79.4 \%$. Regressing $B W$ on $B L, H G$, and $H W$ measurements gave statistically significant $(P<0.01)$ equations for breeds and class of stock, with $R^{2}$ ranging from 0.778 to 0.973 . The regression coefficients of the separate equations for breed and class of stock were different $(P<0.001)$ with $R^{2}$ values ranging from 0.778 to 0.973 and 0.881 to 0.953 respectively. The inclusion of $B L, H G$, and HW improved the model fit for breeds and classes of stock. The second stepwise regression procedure excluded BL and this improved the model fit for breeds but reduced fit for a class of stock and the overall model. Because of this, we assumed collinearity in data and we tested for multicollinearity, the results of which are presented in Tables 6 and 7 .

Collinearity existed among body measurements at $12.68,41.49,34.20$, and 24.03 for MC, HG, HW, and SC respectively. All the tolerance values were closer to zero than one indicating the presence of multicollinearity among variables. Because collinearity was informed by VIF values we evaluated the Eigenvalues and condition indexes $(\mathrm{Cl})$ of body measurements for affirmation and the results are shown in Table 7. We observed two small eigenvalues of 0.003 , and 0.000 for components 5 and 6 respectively, with variance proportions of $0.56,0.90,0.92$, and 0.83 for $\mathrm{MC}, \mathrm{HG}, \mathrm{HW}$, and SC respectively. The corresponding $\mathrm{Cl}$ was 46.5 (MC) 125.5 $(\mathrm{HG}, \mathrm{HW}$, and $\mathrm{SC})$.

Table 5. Regression equations predicting body weight (BW), heart girth (HG), height at withers (HW), body length (BL) of smallholder beef cattle in Gokwe North.

\begin{tabular}{lllc}
\hline Category & Regression equation & $\mathrm{R}^{2}$ & Adjusted R $^{2}$ \\
\hline *Simple Regression & & & \\
\hline Overall & $\mathrm{BW}=3.091 \mathrm{BL}+44.551$ & 0.604 & 0.600 \\
Overall & $\mathrm{BW}=3.703 \mathrm{HG}-128.922$ & 0.794 & 0.793 \\
Overall & $\mathrm{BW}=4.391 \mathrm{HW}-109.220$ & 0.774 & 0.771 \\
Multiple Linear regression & & & \\
Afrikaner & $\mathrm{BW}=-16.458 \mathrm{HG}+19.193 \mathrm{HW}+4.895 \mathrm{BL}-21.419$ & 0.976 & 0.973 \\
Mashona & $\mathrm{BW}=0.474 \mathrm{HG}+1.024 \mathrm{HW}+1.607 \mathrm{BL}+5.647$ & 0.936 & 0.930
\end{tabular}




\begin{tabular}{|c|c|c|c|}
\hline Tuli & $B W=12.174 \mathrm{HG}-18.564 \mathrm{HW}+6.322 \mathrm{BL} 111.916$ & 0.778 & 0.758 \\
\hline Mature cows & $B W=-5.032 H G+6.230 H W-1.350 B L-964.857$ & 0.881 & 0.865 \\
\hline Bulls & $B W=8.620 H G-9.991 H W+6.39 B L-492.481$ & 0.930 & 0.921 \\
\hline Steers & $B W=-3.240 H G-2.312 H W+6.796 B L+377.778$ & 0.953 & 0.947 \\
\hline Heifers & $B W=5.035 H G+6.233 H W-1.350 B L-646.962$ & 0.891 & 0.876 \\
\hline Overall & $B W=2.409 H G+0.255 H W+1.425 B L-15.269$ & 0.923 & 0.919 \\
\hline \multicolumn{4}{|c|}{ Predicted via HG and HW only } \\
\hline Afrikaner & $B W=-4.393 H G+9.459 H W-59.565$ & 0.917 & 0.911 \\
\hline Mashona & $B W=1.074 \mathrm{HG}+1.800 \mathrm{HW}-0.301$ & 0.925 & 0.920 \\
\hline Tuli & $B W=-4.474 H G+9.548 H W-10.779$ & 0.679 & 0.659 \\
\hline Mature cows & $B W=6.168 H G+8.806 H W-1617.730$ & 0.671 & 0.644 \\
\hline Bulls & $B W=1.206 H G+18.137 H W-2257.037$ & 0.873 & 0.862 \\
\hline Steers & $B W=1.520 H G+4.674 H W-420.491$ & 0.904 & 0.896 \\
\hline Heifers & $B W=6.142 H G+8.810 H W-1084.544$ & 0.771 & 0.744 \\
\hline Overall & $B W=2.493 H G+1.514 H W-132.003$ & 0.802 & 0.798 \\
\hline
\end{tabular}

*Simple linear regression was considered for the overall data and not specific to breeds and class of stock.

Table 6. Variance inflation factors (VIF) and Tolerance values of six body measurements for indigenous cattle in Gokwe North.

\begin{tabular}{llllllll}
\hline Trait & Estimate & SE & Sig. & $R^{2}$ & Tolerance & VIF & Remarks \\
\hline (Constant) & -76.529 & 33.213 & .023 & - & - & - & Collinearity \\
MC & -5.262 & 2.100 & .014 & 0.751 & .079 & 12.678 & Non- collinearity \\
BL & .375 & .509 & .463 & 0.777 & .104 & 9.588 & Collinearity \\
HG & 3.606 & 1.106 & .002 & 0.891 & .024 & 41.491 & Collinearity \\
HW & 1.735 & 1.207 & .154 & 0.880 & .029 & 34.198 & Collinearity \\
SC & -1.313 & 4.003 & .744 & 0.751 & .042 & 24.030 & \\
\hline
\end{tabular}

VIF = variance inflation factors, SE = standard error

Table 7. Eigenvalues, condition indexes $(\mathrm{Cl})$, and variance proportions of body measurements for indigenous cattle in Gokwe North.

\begin{tabular}{|c|c|c|c|c|c|c|c|c|}
\hline \multirow[b]{2}{*}{ Dimension } & \multirow[b]{2}{*}{ Eigenvalue } & \multicolumn{6}{|c|}{ Collinearity Diagnostics } & \multirow[b]{2}{*}{ SC } \\
\hline & & Condition Index & Constant & $\mathrm{MC}$ & $\mathrm{BL}$ & $\mathrm{HG}$ & $\mathrm{HW}$ & \\
\hline 1 & 5.951 & 1.000 & .00 & .00 & .00 & .00 & .00 & .00 \\
\hline 2 & .033 & 13.458 & .50 & .00 & .04 & .00 & .00 & .00 \\
\hline 3 & .008 & 27.108 & .03 & .00 & .14 & .02 & .06 & .04 \\
\hline 4 & .004 & 36.412 & .36 & .06 & .57 & .01 & .01 & .09 \\
\hline 5 & .003 & 46.507 & .05 & .56 & .00 & .07 & .00 & .06 \\
\hline
\end{tabular}




\section{Discussion}

\subsubsection{Breed and class differences in body linear measurements}

The weights and linear measurements observed in this study were within the expected standards for each breed with exceptions. Afrikaner bulls in the current study weigh much less than the acceptable average weight of $745 \mathrm{~kg}$ with HW of $122 \mathrm{~cm}$ and similarly for adult cows $525 \mathrm{~kg}$ (FAO, 2012) Mashona males and females weigh between 350-635 and 260-410 kg respectively (DAD-IS, 2005 ) these figures were also confirmed in the current study. Poor nutrition has been cited as a major constraint in smallholder farming systems (Lukuyu et al. 2016). It is plausible that body sizes for classes of stock in the study reflect stunted growth due to poor nutrition. Little information on the phenotypic characterization of these breeds is available, this has earlier been coined by (Mhlanga, 1999) who reported that there is a total dearth of information on the indigenous livestock genotypes. Similar remarks were also made by Mwai et al., (2015) who inferred that breeding improvement programs of African indigenous livestock remain too few across all African countries, while (Gororo et al., 2017) showed that there is a paucity of information regarding breed and trait preferences for local breeds in Zimbabwe. General information is only indicated on the AGRT website, there is a need to characterize the indigenous breeds' in order to exploit their genetic potential. Various crossbreeding systems have been adopted in which they have been used as suitable maternal lines (Mhlanga, 1999) thus pure breeding for genetic conservation purposes is still limiting the genetic progress of these local breeds. The wider variation in the range of values is also an indication of the fact of wider genetic distances within breeds. There are no deliberate efforts in the identification of genotypes, desirable production attributes, and conservation of superior genotypes within the smallholder farming sector, needless to say, that presumed superior animals are transferred into the commercial herds for crossbreeding. Historically the custodians of purebred cattle were dominated by commercial farmers with strict intentions for uniformity and prepotency among cattle breeds, thus destroying phenotypic and genotypic variation existing in indigenous cattle populations. In spite of this challenge, we advocate for a renewed deliberate effort in selection programs for pure maternal and sire lines for the indigenous breeds and their conservation at research institutions. The differences in body measurements among breeds and classes of stock were anticipated and the current results have shown that the Tuli breed is preferred since it has high values for most of the traits. This also affirms reports by Ndumu et al., 2008) and (Mwai et al., 2015) who concluded that African cattle breeds have higher genetic diversity than cattle breeds in other regions. However these differences are only phenotypic hence there is a need to evaluate the like microsatellite DNA variations to confirm linkage disequilibrium among these breeds (Mbole-Kariuki et al., 2014). A similar study was conducted by (Gororo et al. 2018) and the results were encouraging. From this study it was revealed that there is still a lot of genetic variation among indigenous local breeds, however, this study did not focus on breed superiority or individual traits dominating the local breeds. Local breeds are known to possess survival traits like trypanotolerance (Lemecha et al., 2006), high tolerance to heavy tick infestation, thermostolerance at the cellular and physiological levels (Hansen, 2004), able to withstand very harsh environmental conditions (Mwai et al., 2015), are thought to be able to survive on very poor pasture, scarce water and have good walking abilities (Mwai et al., 2015) but, are still fertile (Gororo et al., 2017) and some of them produce good carcass quality. It is also prudent to note that before any biochemical or genetic characterization on local breeds can be done, morphological markers and productive traits still have the capability to indicate the functional genetic diversity within a population as espoused in the current study.

\subsubsection{Correlation between body linear measurements}

The strong relationship existing between BW and body measurements suggests that either one or a combination of the morphological traits could be used to estimate live weight in cattle fairly well in the situation where weighbridges or scales are not available (Yakubu, 2010). Bodyweight has been observed to be highly correlated $(r=0.90)$ with body length, heart girth, height at withers (Afolayan, Adeyinka, and Lakpini, 2006; Basumatary et al., 2008; Ozkaya and Bozkurt, 2009; Katongole et al., 2013; Lukuyu et al., 2016; Chaturvedani et al., 2017; Tebug et al., 2018; Black and Breed, 2019;) particularly so with heart girth ( $r=0.96)$ (Lukuyu et al., 2016; Chaturvedani et al., 2017). In the current study, the overall BW was highly correlated with HG and HW, however, differences were observed among breeds and classes of stock. The higher correlation values for Mashona cattle are commendable and clearly indicate that body linear measurements can be effective in determining a live weight for this breed. With respect to the class of stock, the correlations vary widely from -0.733 to 0.933 . We observed that BL showed most of the negative correlations with other measurements. These results are inconsistent with Yakubu, (2010) and Babale et al., (2018) however, Bene et al., (2007) reported similar results. It is interesting to note that the positive relationship between body linear measurements and BW in the current study can be a basis for selection programs since they suggest that an improvement in one could lead to a corresponding increase in the other trait (Assan, 2013).

\subsubsection{Regression of body weight on body linear measurements}

The single explanatory variable that explained the most variation in the current study was $\mathrm{HG}$, consistent with previous studies (Dodo et al., 2001; Yan et al., 2009; Lesosky et al., 2012; Lukuyu et al., 2016). The inclusion of BL and HW improved the model fit in the current study. Previous workers found that the addition of BL to HG improved the predictive power of the model (Ozkaya and 
Bozkurt, 2009; Gunawan and Jakaria, 2010), while others have not found it useful (Francis et al., 2002; Goe et al., 2001). In our case, the improvement in the model with all variables is difficult to explain since there is evidence of collinearity among predictor variables. However, we observed that regression modeling for Tuli breed and mature cows had lower $\mathrm{R}^{2}$ values and we presumed this to explain the discrepancies. It is however important to mention the fact that regression explains much of the variation in the current study with quite high $\mathrm{R}^{2}$ values above $65 \%$. We, therefore, subscribe to conclusions by (Lukuyu et al. 2016) that when BW is highly correlated with HG and there is the presence of collinearity among the linear measurements, the inclusion of additional linear measurements to the prediction equation will not increase the predictive power and accuracy of these bodyweight estimates over equations which used HG alone. We also observed that the regression equations for the different breeds and classes of stock were within the $95 \%$ prediction interval of the overall model. This is commendable and we, therefore, promote the hypothesis that the accuracy of estimating BW can still be improved by using separate equations for breed and class of stock.

\subsubsection{Multicollinearity}

The VIF, tolerance higher condition index, and eigenvalues of MC, HG, HW, and SC in the current study indicate the presence of collinearity. The correlation matrix singularity (Yakubu, 2010) exhibited by HG and HW individually or in combination is evidence for collinear variance components. According to Oguntunji and Makram, (2019) correlation coefficient is amongst the diagnostic techniques used to detect multicollinearity among variables. The high VIF values for HG and HW show their level of inflation thus exhibit multicollinearity (Oke et al., 2019). There are no standard VIF values but Yakubu (2010), Jamal, (2017) and Oke et al., (2019) confirmed that if any of the VIF values exceeds 10, it implies multicollinearity. In addition, the tolerance values for HG and HW are the furthest from one, again implying collinearity. The same predictors also have the smallest eigenvalues with the highest corresponding condition number $(\mathrm{Cl})$, which also confirms multicollinearity. Collinearity makes it difficult to come up with reliable estimates (Harshada, 2012) for their individual coefficients which might lead to accurate conclusions about the data. In the current study, the presence of multicollinearity inflated the HG and HW variances and lead to a lack of statistical significance of individual predictor variables although the overall model was significant. This explains the lower $\mathrm{R}^{2}$ values obtained when only these two variables were considered in the regression model. Because of this, we suggest that only one of the variables (Oguntunji and Makram 2019) can be used to predict body weight in beef cattle.

\section{Conclusion}

Body linear measurements varied among breeds and classes of stock. Bivariate correlations between BW and body dimensions of Afrikaner, Mashona, and Tuli cattle were positive and highly significant. Simple regression predictions showed that HG was the only single factor that can accurately estimate BW in cattle. Collinearity existed among body measurements for MC, HG, HW, and SC.

Funding: This research received no external funding

Conflicts of Interest: The authors declare no conflict of interest.

\section{References}

[1] Afolayan, R. A., Adeyinka, I. A., \& Lakpini, C. A. M. (2006). The estimation of live weight from body measurements in Yankasa sheep. Czech Journal of Animal Science, 51(8), 343.

[2] Babale, D. M., Abaya, U. H., \& Gworgwor, Z. (2018). Relationship between liveweights, linear bodymeasurements and cost prices of small ruminantssold in and around Mubi environs, Adamawa .state, Nigeria Journal of Dairy, Veterinary andAnimal Research, 7(6), $273-277$.

[3] Basumatary, R., Ghosh, K., Pathak, P. K., Kanwar, P., Bandopadhyay, S., \& Ghosh, M. K. (2008). Prediction of body weight based on body measurements of Yak. Indian veterinary journal, 85(2), 185-186.

[4] Bene, S., Nagy, B., Nagy, L., Kiss, B. A. L. A. Z. S., Polgár, J. P., \& Szabo, F. (2007). Comparison of body measurements of beef cows of different breeds. Archives Animal Breeding, 50(4), 363-373.

[5] Black O. F, Breed W. (2019) Genetic and phenotypic correlation of production traits in cows Proceedings of the Fourth International Conference Publisher Bulgarian National Multidisciplinary Scientific Network of the Professional Society for Research work. (July).

[6] Chaturvedani, A. K., Sahu, S. S., Choursia, S. K., \& Prakash, O. (2017). Correlation between body weight and linear body measurements in adult female Sahiwal cattle. The Indian Journal of Veterinary Sciences and Biotechnology, 12(03), 90-93.

[7] DAD, I. S., (2005) Afrikaner, Mashona, Tuli http://dad.fao.org/en/home.htm (accessed 06 October 2020)

[8] FAO. Phenotypic characterization of animal genetic resources. Animal Production and Health Guidelines No. 11. Rome. 2012. www.fao.org (accessed 16 December 2020)

[9] Gororo, E., Makuza, S. M., Chatiza, F. P., Gwatibaya, S., Gahadzikwa, P., \& Chidzwondo, F. (2017). The potential of reproductive technologies in breeding smallholder cattle populations in Zimbabwe. International Journal of Livestock Production, 8(10), 168-179.

[10] Francis J., Sibanda S, Kristensen T. (2002) Estimating body weight of cattle using linear body measurements. Zimb Vet J 33:15-21

[11] Goe, M. R, Alldredge J. R, Light D (2001) Use of heart girth to predict body weight of working oxen in the Ethiopian high- lands. Livest Prod Sci 69:187-195

[12] Gororo, E., Makuza, S. M., Chatiza, F. P., Chidzwondo, F., \& Sanyika, T. W. (2018). Genetic diversity in Zimbabwean Sanga cattle breeds using microsatellite markers. South African Journal of Animal Science, 48(1), 128-141. 
[13] Gunawan A, Jakaria J (2010) Application of linear body measurements for predicting weaning and yearling weight of bali cattle. Anim Prod 12:163-168

[14] Hansen, P. J. (2004). Physiological and cellular adaptations of zebu cattle to thermal stress. Animal reproduction science, 82, 349-360

[15] Harshada, J. (2012). Multicollinearity Diagnostics in statistical modelling and remedies to deal with it using SAS. www.cytel.com (accessed 27 November 2020)

[16] Jamal, I. D (2017). Multicollinearity and Regression Analysis, Journal of Physics, Conf. Ser. 949012009

[17] Kashoma, I. P. B., Luziga, C., Werema, C. W., Shirima, G. A., \& Ndossi, D. (2011). Predicting body weight of Tanzania shorthorn zebu cattle using heart girth measurements.

[18] Katongole, C. B., Mpairwe, D., Bareeba, F. B., Mukasa-Mugerwa, E., \& Ebong, C. (2013). Predicting body weight from heart girth, height at withers and body condition score in Bos indicus cattle bulls of Uganda. Livestock Research for Rural Development, 25(3).

[19] Lemecha, H., Mulatu, W., Hussein, I., Rege, E., Tekle, T., Abdicho, S., \& Ayalew, W. (2006). Response of four indigenous cattle breeds to natural tsetse and trypanosomosis challenge in the Ghibe valley of Ethiopia. Veterinary parasitology, 141(1-2), 165-176.

[20] Lukuyu, M. N., Gibson, J. P., Savage, D. B., Duncan, A. J., Mujibi, F. D. N., \& Okeyo, A. M. (2016). Use of body linear measurements to estimate liveweight of crossbred dairy cattle in smallholder farms in Kenya. SpringerPlus, 5(1), 1-14.

[21] Mbole-Kariuki, M. N., Sonstegard, T., Orth, A., Thumbi, S. M., de C Bronsvoort, B. M., Kiara, H., ... \& Tapio, M. (2014). Genome-wide analysis reveals the ancient and recent admixture history of East African Shorthorn Zebu from Western Kenya. Heredity, 113(4), 297-305.

[22] Machila N, Fèvre E. M, Maudlin I, Eisler MC (2008) Farmer estimation of live bodyweight of cattle: implications for veterinary drug dosing in East Africa. Prev Vet Med 17:394-403

[23] Mhlang F. (1999)Indigenous livestock genotypes in zimbabwe. University of zimbabwe department of animal science.1-21.

[24] Moela, A. K. (2014). Assessment of the relationship between body weight and body measurement in indigenous goats using path analysis (Doctoral dissertation, University of Limpopo, Turfloop Campus).

[25] Musa A. M, Elamin K. M, Mohammed S. A, Abdalla H. O (2011) Morphometric traits as indicators for body weight in Sudanese Kenana cattle. Online J Anim Feed Res 1:218-222

[26] Mwai, O., Hanotte, O., Kwon, Y. J., \& Cho, S. (2015). African indigenous cattle: unique genetic resources in a rapidly changing world. AsianAustralasian journal of animal sciences, 28(7), 911.

[27] Ndumu, D. B., Baumung, R., Hanotte, O., Wurzinger, M., Okeyo, M. A., Jianlin, H., ... \& Sölkner, J. (2008). Genetic and morphological characterisation of the Ankole Longhorn cattle in the African Great Lakes region. Genetics selection evolution, 40(5), 467-490.

[28] FAO. Phenotypic characterization of animal genetic resources (2020). Animal Production and Health Guidelines No. 11. Rome. 2012. www.fao.org (accessed 16 December 2020)

[29] Oguntunji, A. O., \& Makram, A. (2019). Fixing multicollinearity in modelling market body weight of Sudani ducks (Cairina moschata) from early age morphometric traits. Agricultural Science \& Technology (1313-8820), 11(4).

[30] Oke, J., Akinkunmi, W. B., \& Etebefia, S. O. (2019). Use of correlation, tolerance and variance inflation factor for multicollinearity test. Glob Sci $J, 7,652-659$

[31] Ozkaya, S., \& Bozkurt, Y. (2009). The accuracy of prediction of body weight from body measurements in beef cattle. Archives Animal Breeding, 52(4), 371-377.

[32] Putra, W. P. B., Hartatik, T., Sumadi, S., and Saumar, H. (2014). Accuracy of heart girth for predicting live weight of Aceh cattle. JurnalllmuIlmu Peternakan, 24 (3), 45-53.

[33] Setiaji, R., Prastowo, S., Prasetiyo, D., \& Widyas, N. (2019, November). Phenotypic and Genetic Correlations of Growth Traits in Bali Cattle Breeding Population. In IOP Conference Series: Earth and Environmental Science (Vol. 372, No. 1, p. 012032). IOP Publishing.

[34] Tebug, S. F., Missohou, A., Sourokou Sabi, S., Juga, J., Poole, E. J., Tapio, M., \& Marshall, K. (2018). Using body measurements to estimate live weight of dairy cattle in low-input systems in Senegal. Journal of Applied Animal Research, 46(1), 87-93.

[35] Yakubu, A. (2010). Fixing multicollinearity instability in the prediction of body weight from morphometric traits of White Fulani cows. Journal of Central European Agriculture. 